\title{
Combined Digital and Traditional Bite Registration
}

\author{
Sadek Bakdach* \\ Consultant Pediatric Dentist, USA \\ *Corresponding author: Sadek Bakdach, Consultant Pediatric Dentist, Chicago, IL 60608, USA
}

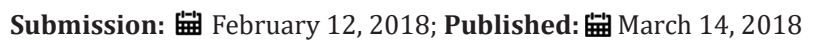

\section{Opinion}

A high percentage of dental restorative procedures failure is attributed to the failure of maintaining the patient's occlusal patterns, and this fact becomes more and more valid as the restoration is more and more extensive. Our need to evaluate the distribution and the quality of occlusal forces is of a growing importance along with our growing knowledge of the masticatory system's sensational perception in the Central Nervous System, keeping in mind that the CNS potential adaptation is of a limited capacity and this is related to some individual factors of the patient (age is a major factor).

\section{Among the symptoms of inaccurate bite registration:}

a) Functional difficulty, may reach the extend of refusal and rejection of the assumed restoration

b) Distortion of speech, swallowing and breathing

c) Headaches, Ear pain, vision distortion, throat and neck pain

d) TMJ disfunction
This concept applies to all kind of restorations including fillings, crowns and bridges, but it is very important in two special cases;

i. Comprehensive Dental Treatment under General Anesthesia

ii. Full mouth rehabilitation

The digital bite registration can give us a good idea about the patient's bite patterns before commencing any procedure, so we have an idea regarding the forces' distribution and what are the needed modifications if any is undoubtedly needed and the quantity and quality of the required modifications.

The added conventional method is to create a stable position of the tray, so we can use it and reuse it as required without taking the risk of a new bite patterns when checks up are repeated. We can use any bite registration semi fluid material (silicon) keeping in mind the fast setting (20 seconds) plasticity and relative stability.

This method will enable us to avoid taking impressions to create models and usage of bite registration papers (blue papers). It is an accurate way to control and study new contact points in a scientific, up to date, readable and reliable procedure (Figure 1).

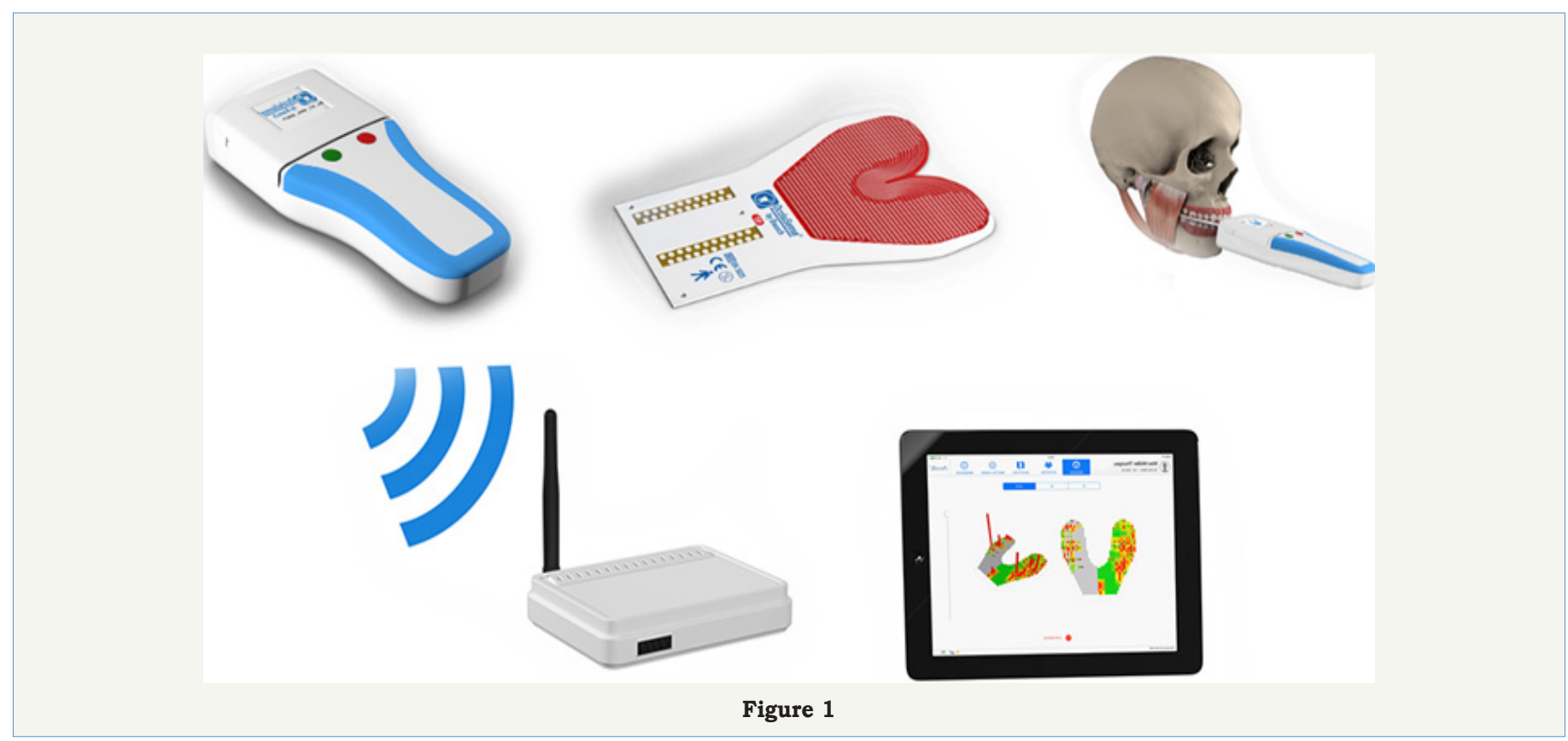


a. Choose the appropriate size of the bite tray

b. Apply material on both sides

c. Reasonable material thickness (4 to $5 \mathrm{~mm}$ )

d. Elimination of material in respect to the presumed treatment areas while trying to preserve tow points of contact on each side or at least one point on each side. e. This technique is still under technical development and needs more clinical trials to achieve its most complete specifications.

Some modifications might be implemented on the used materials (trays) simplifying the data reading and better understanding the brain interpretation to these stimulating signals.
Creative Commons Attribution 4.0

International License

For possible submissions Click Here

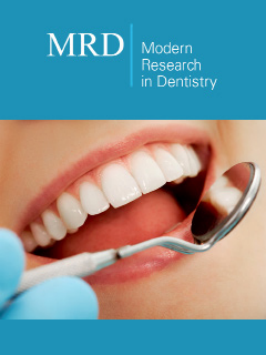

\section{Modern Research in Dentistry}

\section{Benefits of Publishing with us}

- High-level peer review and editorial services

- Freely accessible online immediately upon publication

- Authors retain the copyright to their work

- Licensing it under a Creative Commons license

- Visibility through different online platforms 